\title{
Neuromodulation Based on rTMS Affects Behavioral Measures and Autonomic Nervous System Activity in Children with Autism
}

\author{
Guela E. Sokhadze1, Manuel F. Casanova1,2,3, Desmond P. Kelly2,3, Emily L. Casanova², \\ Brook Russell ${ }^{4}$, and Estate M. Sokhadze ${ }^{1,2^{*}}$ \\ ${ }^{1}$ University of Louisville, Louisville, Kentucky, USA \\ ${ }^{2}$ University of South Carolina, School of Medicine, Greenville, South Carolina, USA \\ ${ }^{3}$ Greenville Health System, Greenville, South Carolina, USA \\ ${ }^{4}$ Clemson University, Clemson, South Carolina, USA
}

\begin{abstract}
Many children with autism spectrum disorder (ASD) exhibit symptoms associated with autonomic nervous system (ANS) dysfunction indicative of low psychophysiological flexibility. It is suggested that ASD symptoms are associated with generalized abnormalities in the central nervous system, including structures and networks involved in the top-down regulation of the ANS. Repetitive transcranial magnetic stimulation (rTMS) has been suggested as a possible therapy to target ANS regulation deficits in ASD. In the current study we used neuromodulation based on rTMS over the dorsolateral prefrontal cortex (DLPFC) to reduce sympathetic arousal and increase parasympathetic activity in children with ASD. In a study on 27 children with autism we administered weekly $0.5 \mathrm{~Hz}$ rTMS bilaterally over the DLPFC with concurrent recording of autonomic activity. Statistical analysis of time and frequency domain heart rate variability (HRV) indices and skin conductance level (SCL) revealed a strong linear regression of most HRV and SCL measures. Several parental behavioral rating scores improved post-TMS and showed a correlation with autonomic outcomes; in particular, parasympathetic indices of HRV negatively correlated with repetitive and stereotyped behaviors, while sympathetic arousal indices showed positive correlation with the same behaviors. The paper discusses potential neurobiological mechanisms involved in post-TMS autonomic balance and aberrant behavior improvements.
\end{abstract}

Keywords: autism; rTMS; autonomic activity; repetitive and stereotype behaviors; prefrontal cortex

Citation: Sokhadze, G. E., Casanova, M. F., Kelly, D. P., Casanova, E. L., Russell, B., \& Sokhadze, E. M. (2017). Neuromodulation based on rTMS affects behavioral measures and autonomic nervous system activity in children with autism. NeuroRegulation, 4(2), 65-78. http://dx.doi.org/10.15540/nr.4.2.65

*Address correspondence to: Dr. Estate Sokhadze, Department of Biomedical Sciences, University of South Carolina School of Medicine Greenville, GHS Pediatrics, 200 Patewood Dr., Ste A200, Greenville, SC 29615, USA. Email: sokhadze@greenvillemed.sc.edu

Copyright: (c) 2017. Sokhadze et al. This is an Open Access article distributed under the terms of the Creative Commons Attribution License (CC-BY).
Edited by:

Rex L. Cannon, PhD, Knoxville Neurofeedback Group, Knoxville, Tennessee, USA

Reviewed by:

Rex L. Cannon, PhD, Knoxville Neurofeedback Group, Knoxville, Tennessee, USA

Randall Lyle, PhD, Mount Mercy University, Cedar Rapids, lowa, USA

\section{Introduction}

Autism spectrum disorder (ASD) is characterized by deficits in social interaction and communication as well as restricted, repetitive, and stereotyped behavioral patterns (APA, 2013). A frequently reported symptom of $A S D$ is autonomic nervous system (ANS) dysfunction observed during exposure to sensory stimuli, engagement in social interaction, and resting state. Children and adolescents with ASD have been reported to have high sympathetic tone and low parasympathetic tone compared to controls (Benevides \& Lane, 2015; Kushki, Brian, Dupuis, \& Anagnostou, 2014; Ming et al., 2011; Ming, Julu, Brimacombe, Connor, \& Daniels, 2005). This abnormal autonomic balance is indicative of low psychophysiological flexibility and rigid social communication ability (Thayer \& Lane, 2000). An extensive body of literature suggests that ASD symptoms are associated with generalized abnormalities in the central nervous system, including structures and networks involved in "topdown" control of the ANS. For example, ASD has been associated with pathological findings in 
structures that play a crucial role in modulating the ANS response, including the amygdala, anterior cingulate cortex, and insula (Loveland, Bachevalier, Pearson, \& Lane, 2008). According to recent studies, ASD may be associated with autonomic arousal typical for anxiety that is most consistent with sympathetic overarousal and parasympathetic underarousal (Kushki et al., 2013). According to some authors, anxiety in people diagnosed with autism should be recognized for its direct links with atypical autonomic control and excessive sympathetic arousal (Gillott, Furniss, \& Walter, 2001; Helverschou \& Martinsen, 2011). The ANS is responsible for multiple physiological responses, and dysfunction of this system is often hypothesized as contributing to abnormal cognitive, affective, and behavioral responses in children with autism (Benevides \& Lane, 2015; Smeekens, Didden, \& Verhoeven, 2015). Exploring the relationship between ANS function and social competence is important to gaining an understanding of how dysregulation of autonomic activity may adversely affect social functioning in individuals with ASD.

\section{Transcranial magnetic stimulation (TMS)-based neuromodulation}

Repetitive transcranial magnetic stimulation (rTMS) has been suggested by our group as a therapeutic attempt at overcoming ANS regulation deficits typically observed in individuals with ASD (Casanova et al., 2014; Hensley, El-Baz, Casanova, \& Sokhadze, 2013; Hensley et al., 2012). In the current study we propose using low-frequency rTMS over the dorsolateral prefrontal cortex (DLPFC) to reduce sympathetic arousal and increase parasympathetic activity, thus improving autonomic balance in children with ASD. The approach uses rTMS to induce changes in ANS activity (shown in our preliminary results, Casanova et al., 2014; Wang et al., 2016) to lower aberrant behavior, stereotyped and repetitive behaviors, and anxiety symptoms as well as to improve social awareness and social cognition children with ASD.

TMS operates based on Faraday's law of electromagnetic induction, which describes the process by which a changing magnetic field induces the flow of electric current in a nearby conductor, preferentially one standing at a $90^{\circ}$ angle to the magnetic field. Studies have indicated that lowfrequency or "slow" rTMS $(<1 \mathrm{~Hz})$ increases inhibition of the stimulated cortex through activation of inhibitory cortical circuits (Pascual-Leone, Walsh, \& Rothwell, 2000). The proposed mechanism of post-TMS effects on autonomic arousal may include improved normative tonic frontolimbic inhibitory influences known to be deficient in autism (Bachevalier \& Loveland, 2006; Loveland et al., 2008). We hypothesized that slow rTMS stimulation applied to the DLPFC will lower sympathetic arousal and normalize autonomic balance.

Theoretical rationale for the proposed intervention was based on a "minicolumnar" neuropathological model of autism (reviewed in Casanova, Sokhadze, Opris, Wang, \& Li, 2015). Prior studies from our group suggest that supernumerary minicolumns and reduced cell size of pyramidal cells biases corticocortical connections in favor of short (i.e., arcuate) projections at the expense of longer ones (i.e., long association fibers). Furthermore, the abnormal width of minicolumns in autism reflects primarily a loss of the inhibitory tone of anatomical elements surrounding this modular structure, resulting in a reduced lateral inhibition effect (Casanova, 2005, 2006; Casanova, Buxhoeveden, \& Brown, 2002; Casanova et al., 2006). The minicolumnar abnormalities are even more pronounced in the prefrontal cortex (PFC), resulting in weakened frontal control of other cortical and subcortical networks, including those involved in regulating ANS arousal (Casanova et al., 2014, 2015). We theorize that contrary to other inhibitory cells (such as basket cells and chandelier cells whose projections keep no constant relation to the surface of the cortex), the geometrically exact orientation of double-bouquet cells and their location at the periphery of the minicolumn (inhibitory surround) make them an appropriate candidate for induction by a magnetic field applied parallel to the PFC. Over a course of treatment, slow rTMS may selectively depotentiate enhanced synaptic weights associated with pathological conditions, and in the case of ASD it may lower the cortical excitation/inhibition ratio.

\section{Review of autonomic dysfunctions in autism}

Cardiac activity. In autism, ANS dysfunction includes blunted cardiac responses to visual and auditory social stimuli (Hirstein, Iversen, \& Ramachandran, 2001; Palkovitz \& Wiesenfeld, 1980). These responses are important for understanding social situations and awareness of social context during communication (Jansen et al., 2000). Developmental deficits in autonomic regulation of the cardiac activity in children with autism may result in a lower ability to engage in social communication (Porges, 2003; Porges, Doussard-Roosevelt, Portales, \& Greenspan, 1996). In addition to increased sympathetic tone, a decrease in cardiac parasympathetic tone has been often reported in ASD (Kushki et al., 2013, 2014; Ming et al., 2005, 2011; Ming, Julu, Wark, 
Apartopoulos, \& Hansen, 2004). Julu et al. (2001) reported reduced cardiac vagal tone, decreased baroreflex sensitivity, and unstable respiratory rhythm in individuals diagnosed with autism. The respiratory dysrhythmia in children with ASD, according to Ming, Patel, Kang, Chokroverty, and Julu (2016), is a phenomenon associated with lower cardiac vagal activity. Both respiratory and cardiac vagal control hypofunction in ASD may suggest a brainstem dysfunction or diminished top-down control of the PFC over limbic and subcortical structures (Bachevalier \& Loveland, 2006; Loveland et al., 2008). Low parasympathetic activity can help explain chronic sensory hyperarousal and some of the social communication difficulties in children with ASD. This hypothesis is concordant with Porges' "polyvagal theory" (Porges, 2003, 2011) that emphasizes the important role of both efferents and afferents of the vagus nerve in support of social engagement and communication. The inhibitory parasympathetic vagus nerve acts as a vagal "brake" that slows heart rate (HR). Such modulation of HR enables rapid engagement and disengagement with objects and people, a skill important for promoting social behaviors (Porges, 1995, 2003).

Time and frequency domain-based analysis of heart rate variability (i.e., HRV) represents a measure commonly used in psychopathology research for assessment of cardiac autonomic control (Berntson et al., 1997; Cohen, 2000; Thayer \& Friedman, 2002). Attenuated spectral power of high frequency (HF) component of HRV, frequently used as an index of parasympathetic control, is an indicator of limited psychophysiological flexibility (Berntson et al., 1997; Cohen et al., 2000; Movius \& Allen, 2005; Thayer, Ahs, Fredrikson, Sollers, \& Wager, 2012). Children diagnosed with ASD have been found to have deficits in suppression of HF component of HRV during social tasks, compared to controls (Althaus, Mulder, Mulder, Aarnoudse, \& Minderaa, 1999; Hutt, Forrest, \& Richer, 1975). Furthermore, children with ASD demonstrate dampened HR reactivity, unusually small deceleratory HR responses, and generally low cardiac reactions to auditory stimulation including socially relevant speech, phrases, and tones (Corona, Dissanayake, Arbelle, Wellington, \& Sigman, 1998; Palkovitz \& Wiesenfeld, 1980; Zahn, Rumsey, \& Van Kammen, 1987). Kleberg (2015) emphasized that atypical autonomic arousal has been used to explain some of the core symptoms of ASD. In effect, it has been hypothesized that either elevated or attenuated tonic arousal was a causal factor behind some of the core autism symptoms, such as repetitive behaviors
(Hirstein et al., 2001; Toichi \& Kamio, 2003; Toichi et al., 1999) and avoidance of social interaction (Rogers \& Ozonoff, 2005). According to other current theories, atypical regulation of arousal could cause impairment in attention, another symptom commonly associated with ASD (Orekhova \& Stroganova, 2014). A series of current studies of autonomic dysfunctions in ASD were reported in the literature showing drastically increased interest in the investigation of autonomic system functioning abnormalities in children with autism (Benevides \& Lane, 2015; Cohen, Masyn, Mastergeorge, \& Hessl, 2015; Kleberg, 2015; Kushki et al., 2013, 2014; Patriquin, Lorenzi, \& Scarpa, 2013; Smeekens et al., 2015). As noted by Rees (2014), there is an urgent need to recognize the importance of the ANS in pediatrics, not limited to neurodevelopmental disorders.

Electrodermal activity. Electrodermal activity is a commonly used measure in psychophysiology and cognitive neuroscience research as it reflects sympathetic neural responses independent of direct parasympathetic control, or as its activity may reflect effects of adrenaline (Boucsein, 2012; Williams et al., 2004). Studies of skin conductance level (SCL) in autism have demonstrated several manifestations of abnormal sympathetic function (Ming et al., 2004, 2005, 2011, 2016). Classical psychophysiological studies of skin conductance response (SCR) in children with autism have shown a lack of the normal habituation in the magnitudes of SCR to the same stimulus presented over time, and they demonstrate poor adaptation to a repeated stimulus (Barry \& James, 1988; van Engeland, 1984). Furthermore, higher tonic electrodermal activity, as well as larger SCRs to sounds, was observed in autistic children compared to controls (Barry \& James, 1988). Palkovitz and Wiesenfeld (1980) did not find differences in electrodermal reactivity to auditory stimulation compared to controls, but reported that the autistic group had a higher baseline SCL. In addition, it has been reported that children with autism had blunted autonomic arousal to visual and auditory social stimuli (Hirstein et al., 2001; Ming et al., 2016; Zahn et al., 1987). Several of our own pilot studies reported excessive but less differentiated SCR to affective sounds, visual, and audio-visual stimuli in various affective stimulation tests (Dombroski et al., 2014; Sokhadze et al., 2012). Since SCL is controlled solely by sympathetic inputs, the above effects are indications of high sympathetic tone and at the same time relatively low selectivity of ANS responses to sensory stimuli in autism. High sympathetic reactivity to sound may underlie the atypical 
behavioral responses to sound often demonstrated by children with ASD (Chang et al., 2012).

Liss, Saulnier, Fein, and Kinsbourne (2006) suggested that the overfocused attentional style in ASD may be the result of hyperarousal, while Keehn, Müller, and Townsend (2013) hypothesized that atypical behavioral arousal regulation in persons with ASD results from early deficits in disengaging attention. The term "arousal" was originally used to describe both behavior and physiological activity, including its cortical and autonomic components (Lacey \& Lacey, 1970). The most widely used measures of autonomic arousal are the tonic SCL and spontaneous and stimulus-related fluctuations in electrodermal activity along with reduced HRV. Schoen, Miller, Brett-Green, and Nielsen (2009) have found that most children with autism had high SCL (high tonic arousal) associated with higher than normal SCR magnitudes, faster latencies, and slower habituation.

\section{Goals of the study}

The aim of this case series study was to investigate the effects of 18 weekly sessions of low-frequency $(0.5 \mathrm{~Hz})$ rTMS over DLPFC on autonomic function measures and on behavioral symptoms (based on parental behavioral reports) in children with ASD. We predicted that the course of rTMS would have positive effects on behavioral rating scores similar to those reported in our prior studies (Casanova et al., 2014; Hensley et al., 2012, 2013; Wang et al., 2016). In particular, based on our pilot studies, we expected that the proposed rTMS therapy would provide for improvements in irritability, hyperactivity, and repetitive stereotyped behavior rating scales on the Aberrant Behavior Checklist (ABC; Aman \& Singh, 1994) and Repetitive Behavior Scale (RBS-R; Bodfish, Symons, \& Lewis, 1999). In addition, we used the Social Responsiveness Scale (SRS-2, Constantino \& Gruber, 2005) to assess changes in social awareness, social cognition, and social motivation. We hypothesized that the behavioral improvement would also be manifested in autonomic measures indicative of lower sympathetic arousal, increased parasympathetic tone, and normalized cardiac autonomic balance.

\section{Methods}

\section{Subjects}

In this study, we investigated the activity of the ANS during rTMS treatment course in 27 children with ASD ( 21 boys and 6 girls, mean age $12.52 \pm 2.85$ years). Participants with ASD were recruited through the University of Louisville Weisskopf Child Evaluation Center (WCEC). Diagnosis was made according to the DSM-IV-TR and further ascertained with the Autism Diagnostic Interview-Revised (ADIR; LeCouteur, Lord, \& Rutter, 2003) by a clinical psychologist, who also did pre- and post-TMS behavioral evaluations using $A B C$, RBS-R, and SRS-2. Children with a history of a seizure disorder, significant hearing or visual impairment, identified brain abnormality, identified genetic disorder, or comorbid severe psychopathology were excluded. Subjects were excluded at the intake stage if they were unable to tolerate TMS or autonomic monitoring procedures such as placement of adhesive electrodes and sensors on their skin. Medication of enrolled subjects was monitored, but subjects were not taken off prescribed medications.

All participants were high-functioning children with ASD and with full-scale IQs $>80$ assessed using the Wechsler Intelligence Scale for Children, Fourth Edition (WISC-IV; Wechsler, 2004). Twenty-nine ASD subjects out of 32 enrolled in the study completed all 18 sessions of rTMS. Two subjects had excessive gross movements and artifacts affecting autonomic activity recording and their data were not entered into final analysis.

The study complied with all relevant national regulations and institutional policies and has been approved by the local Institutional Review Board (IRB). Participating subjects and their parents were provided with full information about the study including the purpose, requirements, responsibilities, reimbursement, risks, benefits, alternatives, and the role of the local IRB. The consent and assent forms approved by the IRB were reviewed and explained to all subjects who expressed interest in participating. All questions were answered before consent/assent signature was requested. If the individual agreed to participate, both the child and parent/guardian signed and dated the informed consent/assent forms and received a copy countersigned by the investigator who obtained consent. 


\section{Low-frequency rTMS procedure}

A trained electrophysiologist delivered rTMS using a Magstim Rapid system (Magstim Co, Whitland, UK). Participants were seated in a reclining chair and fitted with a swimming cap. Motor threshold at the first session was detected by mild supra-threshold stimulations administered over the left motor cortex to determine the optimal area for stimulation of the abductor pollicis brevis muscle of the right hand. The output of the machine was increased by $7 \%$ each time until the least amount of machine power that induced a $50-\mu \mathrm{V}$ deflection or a visible twitch was identified in four out of five trials over the cortical area controlling the contralateral abductor pollicis brevis muscle. Surface electrodes were attached over the abductor pollicis brevis and first dorsal interossei areas. Electromyographic (EMG) responses (motor-evoked potentials) were recorded using the C2 J\&J Engineering Inc. (Poulsbo, WA) physiological data acquisition system with USE software interfaced with Magstim TMS device. Similar procedure was applied to determine motor threshold for the right hemisphere. The TMS treatment course was administered once per week for 18 weeks over the DLPFC (six over the left, six over right, and the last six sessions equally distributed the number of pulses over the both left and right hemispheres). The site for stimulation was placed $5 \mathrm{~cm}$ anterior to and in a parasagittal plane to the site of maximal abductor pollicis brevis stimulation. The figure-eight coil, with a 70-mm wing diameter, was kept flat over the scalp. Stimulation was performed at $0.5 \mathrm{~Hz}$ and $90 \%$ of resting motor threshold, with a total of 160 pulses per day (eight trains of 20 pulses, with a 20 -s interval between trains; for additional details, see Casanova et al., 2012, 2014; E. Sokhadze et al., 2009, 2016; G. Sokhadze et al., 2012).

\section{ANS monitoring}

Physiological activity was monitored and recorded from subjects during each rTMS session. Additionally, several minutes of baseline and postbaseline activity was recorded before and after each TMS session. However, for data analysis in this particular study we included only data recorded during the administration of TMS. HRV measures were calculated from 10-min segments derived from an artifact-free electrocardiogram (ECG) recording and mean SCL. Integrated EMG was used to detect movement-related artifacts. ECG, EMG, pneumogram, and electrodermal activity were acquired (1024- $\mathrm{Hz}$ sampling rate for EMG and ECG, $128 \mathrm{~Hz}$ for pneumogram and electrodermal activity) by a C-2 J\&J Engineering Inc. physiological monitoring system with USE-3 software (Physiodata,
Poulsbo, WA). Three $\mathrm{Ag} / \mathrm{AgCl}$ electrodes (El-503, Biopac Systems, Inc., CA) were attached for measurement of Lead II ECG, three $\mathrm{Ag} / \mathrm{AgCl}$ electrodes (EL-501 from Biopac) for EMG recording from the right hand, and pneumogram was recorded with a strain gauge transducer (J\&J Engineering). Electrodermal activity was recorded by $\mathrm{Ag} / \mathrm{AgCl}$ electrodes (EL-507 by Biopac with Unibase isotonic gel) attached to the distal phalanx of index and middle fingers to measure SCL. Average R-R intervals in ECG (RR), standard deviation of all normal R-R intervals (SDNN), square root of the mean of the squares of successive RR interval differences (RMSSD, or the average change in interval between beats); frequency domain HRV measures such as power of high-frequency (HF), low-frequency (LF), very low-frequency (VLF) components, and the ratio of the LF over the HF (LF/HF ratio is used as an indirect autonomic balance index) of HRV were calculated as time domain and frequency domain cardiac activity measures (Kleiger, Stein, \& Bigger, 2005). Artifactcorrected $\geq 5$-min-long recording epochs were analyzed with fast Fourier transform (FFT) to assess HRV. Integrals of the spectrum in $0.003-0.040 \mathrm{~Hz}$ (VLF of HRV), $0.04-0.15 \mathrm{~Hz}$ (LF of HRV), and 0.15$0.40 \mathrm{~Hz}$ (HF of HRV) bands were measured (in $\mathrm{ms}^{2}$ ). All HRV data was analyzed offline using Kubios HRV software version 2.0 (University of Kuopio, Finland).

HRV interpretation was based on the following concepts: (1) the HF component of HRV is often referred to as respiratory sinus arrhythmia and is assumed to be the noninvasive index of parasympathetic influences on the heart (Berntson et al., 1997; Sohn, Sokhadze, \& Watanuki, 2001); (2) the LF component of HRV has been linked to sympathetic nervous system activity and sympathovagal balance by numerous studies (Malliani, Pagani, \& Lombardi, 1994; Pagani et al., 1986). Other studies have shown that the LF variability is rather a reflection of both sympathetic and vagal influences related to baroreflex mechanisms (Berntson et al., 1997). It is thought that changes in blood pressure amplitude may cause vagallymediated baroreflex responses as well as changes in LF variability. Respiration rate on a per minute basis and peak respiration frequency were calculated. These measures were used to control $\mathrm{HF}$ peak in HRV related to respiratory frequencies in HRV and were not used as dependent measures. 


\section{Statistical analysis}

The primary statistical analyses included linear regression plot estimation of each autonomic dependent variable (RR, SDNN, RMSS; VLF, LF, and $\mathrm{HF}$ of $\mathrm{HRV}$; LF/HF index) over 18 sessions of rTMS course as well as paired sample student's $t$ test of pre- and post-TMS behavioral measures (ABC, RBS-R, SRS-2). For each behavioral rating score analyzed using paired sample student's $t$-test, normality of distribution test was performed to ensure appropriateness for the $t$-test. To estimate the power of the test for the linear regression analysis, statistical results also included values of observed power at $\alpha \square=0.05$ and, when appropriate, their comparisons to the desired power of 0.80 . Actual $R, R^{2}$, and adjusted $R^{2}$ values are reported for each dependent variable in regression analysis. In addition, we analyzed mean changes of autonomic measures from the first to the last session of the rTMS course. The changes of physiological variables (time and frequency indices of HRV and $\mathrm{SCL})$ were entered in a correlation analysis (Pearson correlation) with changes of behavioral evaluation scores of ABC, RBS-R, and SRS-2. SPSS and SigmaStat statistical software packages were used for analysis.

\section{Results}

\section{Behavioral evaluations post-TMS}

As expected based on our prior studies, the $A B C$, RBS-R, and SRS-2 parental behavioral checklists' rating changes showed statistically significant improvements in several domains. Lethargy/Social Withdrawal subscale of the ABC (Aman \& Singh, 1994) showed a significant score reduction, mean decrease $-2.21 \pm 3.58, t(26)=-2.69, p=.015$. Hyperactivity score of the ABC also showed reduction, $-4.79 \pm 7.34, t(26)=-2.84, p=.011$. Inappropriate Speech score decreased as well, $-1.63 \pm 2.92, t(26)=2.49, p=.028$. Stereotypy behavior scores had a marginal decrease that did not reach a significant level, $-2.26 \pm 4.78, t(26)$ $=-2.06, p=.054$.

We found a significant decrease in stereotypic, repetitive, and restricted behavior patterns following 18 sessions of bilateral rTMS as measured by the RBS-R (Bodfish et al., 1999). Total RBS- $R$ score decreased, $-4.21 \pm 5.59, t(26)=-3.28, p=.015$. Stereotypic Behavior subscale showed a significant decrease, $-0.95 \pm 1.26, t(26)=-3.25, p=.004$; and Ritualistic/Sameness Behavior subscale scores showed a decrease, $-0.94 \pm 1.74, \quad t(26)=2.36, p$ $=.03$. Compulsive Behavior subscale also demonstrated a significant decrease, $-1.26 \pm 2.46$, $t(26)=-2.23, p=.039$. Analysis of Social Responsiveness Scale (SRS-2; Constantino \& Gruber, 2005) revealed changes in several subscale rating scores. Social Awareness score of the SRS-2 improved post-TMS, $-7.03 \pm 7.96, t(26)=-4.51, p$ $<.001$; along with Social Cognition, $-8.19 \pm 7.22$, $t(26)=-5.47, p=.001$; and Social Motivation rating scores, $-6.73 \pm 9.42, t(26)=-3.64, p=.001$.

\section{Autonomic activity measures}

Time domain measures of HRV (RR intervals, standard deviation of RR [SDNN], HR RMSSD). Cardiointervals in ECG (RR intervals) showed a statistically significant linear regression over sessions of rTMS, $R=.70, R^{2}=.50$, adjusted $R^{2}$ $=.47, F=15.11, p=.001$, power of performed test (hereafter referred as power) $=0.88$ at $\alpha=0.05$ (Figure 1). Standard deviation of RR (SDNN) intervals showed a statistically significant linear increase over rTMS course, $R=.74, R^{2}=.54$, adjusted $R^{2}=.52, F=19.38, p<.001$, power $=0.95$ at $\alpha=0.05$ (Figure 2). Paired sample $t$-test showed that increase of SDNN from the first to the last session of rTMS course was significant, $29.3 \pm 56.4$ $\mathrm{ms}, t(26)=2.26, p=.036$. Root mean square standard deviation of RR (RMSSD) also showed linear increase, $R=.66, R^{2}=.44, F=12.52, p$ $=.003$, power $=0.87$ at $\alpha=0.05$. The $t$-test yielded a significant increase of RMSSD, $27.78 \pm 48.84$ bpm, $t(26)=2.48, p=.023$.

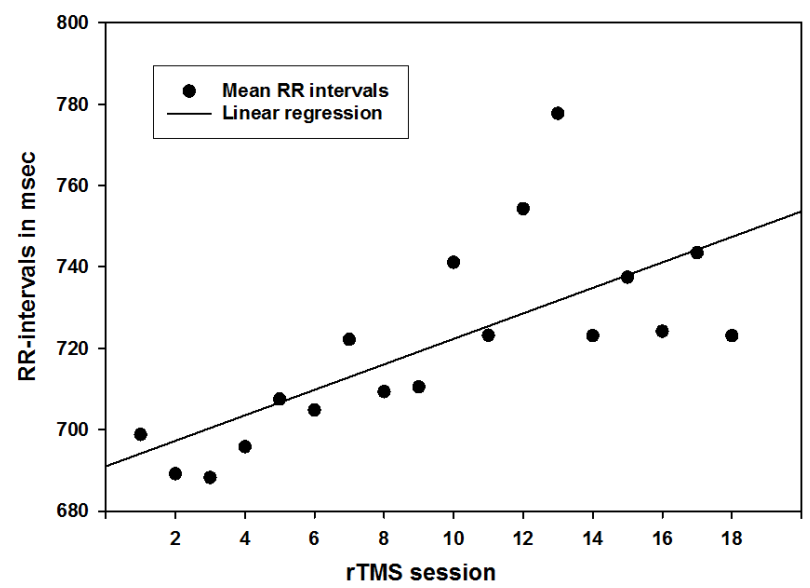

Figure 1. Mean RR intervals over 18 sessions of rTMS in children with autism spectrum disorder. $R=.70, R^{2}=.49, F=15.1, p<.001$, power $=0.92$. 


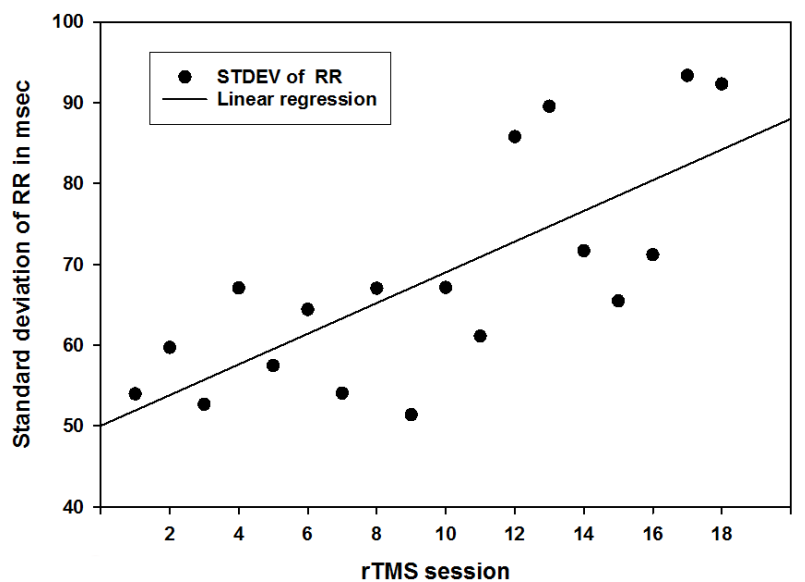

Figure 2. Standard deviation of RR intervals over 18 sessions of rTMS in children with autism spectrum disorder.

$R=.74, R^{2}=.55, F=19.3, p<.001$, power $=0.95$.

Frequency domain measures of HRV (VLF, LF and HF of HRV, LF/HF ratio). The power of the VLF component of HRV did not show any linear regression trend, $F=0.14, p=.71$. The power of the LF component of HRV showed a marginal trend towards linear regression, $R=.50, R^{2}=.25$, adjusted $R^{2}=.21, F=5.43, p=.033$, power $=0.57$ at $\alpha=$ 0.05 , below desired power level of 0.80 (Figure 3 ). The HF component of HRV showed a statistically significant linear increase in power, $R=.64, R^{2}$ $=.41$, adjusted $R^{2}=.37, F=11.25, p=.004$, power $=0.84$ at $\alpha=0.05$ (Figure 4). Increase of the HF power was confirmed by paired sample $t$-test, $865 \pm$ $1418 \mathrm{~ms}^{2}, t(26)=2.66, p=.016$.

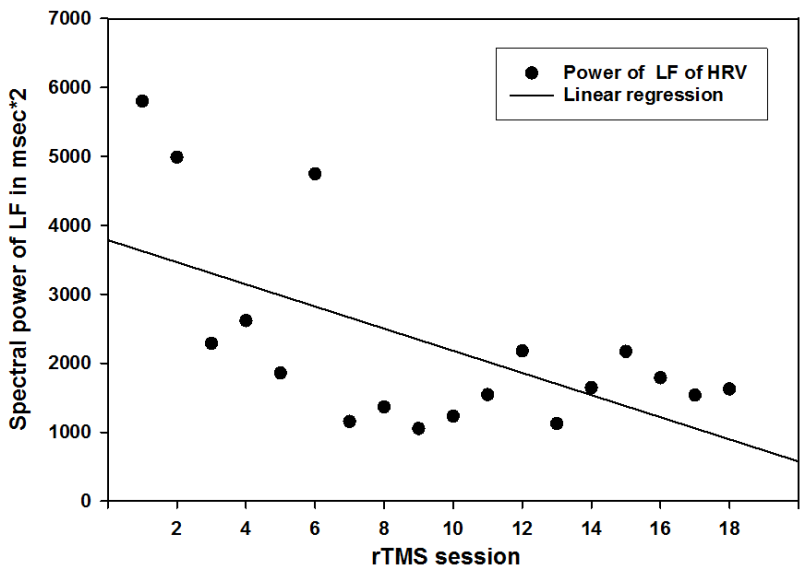

Figure 3. Power of low frequency (LF) of heart rate variability (HRV) over 18 sessions of rTMS in children with autism spectrum disorder.

$R=.50, R^{2}=.25, F=5.44, p=.033$, power $=0.57$.

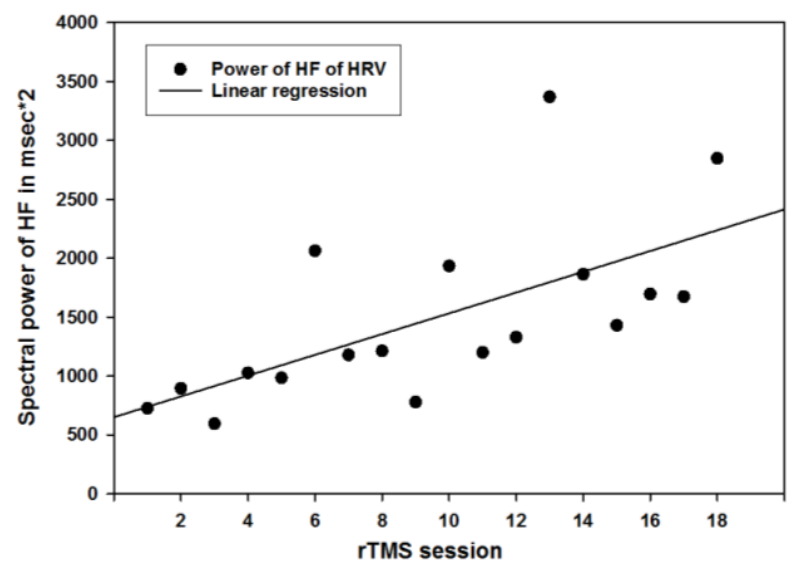

Figure 4. Power of high frequency (HF) of heart rate variability (HRV) over 18 sessions of rTMS in children with autism spectrum disorder.

$R=.64, R^{2}=.41, F=11.2, p=.004$, power $=0.84$.

The LF/HF ratio of HRV (cardiac autonomic balance index) showed a linear regression that was statistically significant, $R=.79, R^{2}=.62$, adjusted $R^{2}$ $=.59$, observed power $=0.97$ at $\alpha=0.05$ (Figure 5). The LF/HR ratio of HRV tended to decrease from the first to the last session of rTMS but failed to reach statistical significance, $-0.42 \pm 1.07, t(26)=-1.72, p$ $=.103$.

Skin conductance level (SCL). SCL showed statistically significant linear regression over 18 sessions of rTMS, $R=.63, R^{2}=.40$, adjusted $R^{2}$ $=.36, F=10.70, p=.004$, power $=0.94$ at $\alpha=0.05$ (Figure 6).

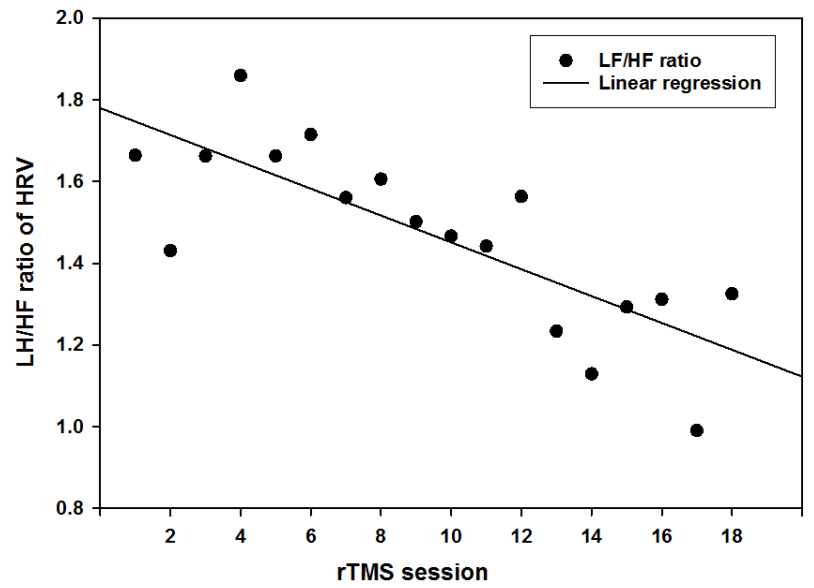

Figure 5. Mean low frequency/high frequency (LF/HF) ratio of heart rate variability (HRV) over 18 sessions of rTMS in children with autism spectrum disorder. $R=.79, R^{2}=.62, F=26.3, p<.001$, power $=0.98$. 


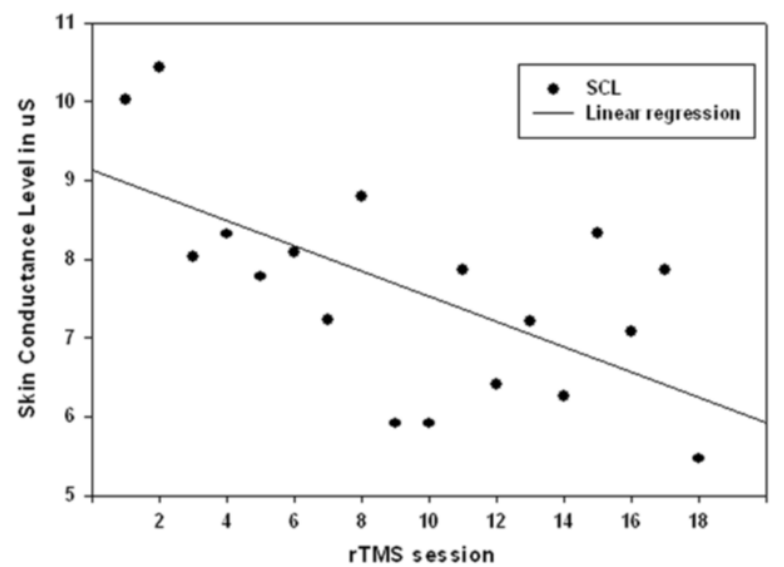

Figure 6. Skin conductance level (SCL) over 18 sessions of rTMS in children with autism spectrum disorder.

$R=.63, R^{2}=.40, F=10.7, p=.005$, power $=0.93$.

Correlation of changes in HRV and SCL measures with behavioral score changes

Several time domain measures of HRV associated with increased HRV showed significant negative correlation with Stereotypy rating of the ABC (SDNN, $r=-0.73, p=<.001$; RMSSD, $r=-0.69, p=.001$ ). The LF component of HRV showed positive correlation with Stereotypy rating changes $(r=0.76$, $p<.001)$. In a similar manner, correlation of Total Repetitive and Stereotyped Behaviors score changes on the RBS-R questionnaire showed negative correlation with time domain measure (RMSSD of HR) changes $(r=-0.51, p=.028)$, but positive correlation with LF/HF ratio $(r=0.58, p$ $=.008$ ). Skin conductance changes showed positive correlation with the Total Repetitive and Stereotyped Behavior of RBS-R $(r=0.56, p=.017)$. There were no significant correlations found between individual HRV and SCL measures and SRS-2 rating score changes.

\section{Discussion}

The most notable result of the study is a replication of the findings in our prior case series studies (Casanova et al., 2014; Wang et al., 2016) reporting improvements in aberrant, stereotyped, and repetitive behaviors. In addition, we found improvements in social awareness, social cognition, and social motivation ratings of the SRS-2 questionnaire. Furthermore, there was a linear increase of $\mathrm{HR}$, as well as both time and frequency domain measures of HRV. Our post-TMS HRV and SCL outcomes point to a decrease of sympathetic arousal and to an increase of parasympathetic activity resulting in a trend of normalization of the autonomic balance. The demonstration of decreased sympathetic arousal, as indexed by decrease of LF and LF/HF of HRV and decreased electrodermal activity posttreatment, is also an important finding. Considering that sympathetic activation is often associated with autonomic arousal, abnormalities of arousal regulation should become one of the main aims of autism research and treatment.

In a study by Hirstein et al. (2001) children with autism mainly had higher than normal baseline SCL and high-amplitude SCRs. In the majority of the children, however, SCL and SCR magnitude dropped below the values observed in normal control groups as soon as they became involved in self-stimulatory activities (such as putting their hands in a bowl of dry beans). Stereotyped and repetitive motor behaviors, one of the core features of autism, has been proposed to be a coping response to reduce hyperresponsive sympathetic activity (Hirstein et al., 2001; Toichi \& Kamio, 2003; Toichi et al., 1999). Arousal dysregulation in autism may manifest in two distinct modes of functioning. The first mode is characterized by elevated tonic arousal, anxiety, and difficulties in focusing attention. The second mode is reflected in reduced tonic arousal, self-stimulatory activities, and decreased awareness of the surroundings. Our results showed a positive correlation of LF of HRV with Stereotypy ratings on $\mathrm{ABC}$ and a positive correlation of LF/HF index with Total Repetitive and Stereotyped Behaviors scores on RBS-R. At the same time we found negative correlations of Stereotyped Behavior scores on both $A B C$ and RBS-R with such HRV measures as SDNN, RMSSD, and standard deviation of HR. These finding are supportive of hypotheses proposing that stereotyped repetitive behaviors can be considered as a coping mechanism for reducing sympathetic overactivation and alleviating anxiety in children with ASD.

How does prefrontal rTMS affect autonomic functions? Only a few studies have looked at the effects of rTMS on the autonomic system, despite the fact that many frontal cortical areas are directly implicated in ANS control (Czéh et al., 2002; Filippi, Oliveri, Vernieri, Pasqualetti, \& Rossini, 2000). It has been reported that there might be neurohumoral changes after treatment with rTMS (Beh-Shachar, Belmaker, Grisaru, \& Klein, 1997). There is also a hypothesis suggesting that the anxiolytic effects of rTMS may act through normalization of hypothalamic-pituitary-adrenocortical (HPA) axis (Holsboer, 2000). Chronic rTMS-induced changes in 
stress-related corticotropin and corticosterone levels have been found in animal models providing support for the suggestion that frontal brain exposure to rTMS may attenuate the activity of the HPA system (Hedges et al., 2002). It was shown that lowfrequency rTMS can influence autonomic balance assessed using HRV (Yoshida et al., 2001). Udupa et al. (2007) reported HRV measures indicating that rTMS produced significant reduction in the cardiac sympathetic/vagal ratio, suggesting improvement in sympatho-vagal cardiac balance, an effect similar to our findings. Lower post-TMS sympathetic activity was reported in the study of Jenkins, Shajahan, Lappin, and Ebmeier (2002).

We propose that it is possible that rTMS effects are mediated through frontolimbic connections. The limbic system is a complex network of structures central to anxiety and mood regulation (Seminowicz et al., 2004). Originally rTMS was investigated as a potential antidepressant therapeutic device under the assumption that magnetic stimulation of the PFC would engage the connected limbic regions involved in mood and anxiety regulation (George, Lisanby, \& Sackeim, 1999). The hypothesis is consistent with PFC rTMS modulating the function of frontolimbic circuits and subcortical structures controlling autonomic activity.

The effects of rTMS on the ANS may also result from a change of cortical excitation/inhibition balance. Several studies outlined a disruption in the cortical excitation/inhibition ratio in individuals with autism (Casanova, 2006; Casanova et al., 2002; Casanova, Buxhoeveden, \& Gomez, 2003; Rubenstein \& Merzernich, 2003). One possible explanation for an increase in the cortical excitation/inhibition bias in ASD is the finding of abnormalities in cortical minicolumns (Casanova, 2005). Double-bouquet cells in the peripheral neuropil space of minicolumns impose a strong vertically directed stream of inhibition surrounding the minicolumnar core (Mountcastle, 2003). In ASD, our preliminary studies indicate that cortical minicolumns are reduced in size and increased in number, especially within the PFC (Casanova, 2005, 2006; Casanova et al., 2002, 2006, 2012). Disturbances in the ratio of cortical excitation to inhibition may lead to an increase in cortical "noise" which may influence functional cortical connectivity and may hinder the binding of associated cortical areas. It has been proposed that the effect of lowfrequency rTMS arises from increases in the activation of inhibitory circuits (Casanova et al., 2015; Sokhadze et al., 2014). Over a course of treatment rTMS may selectively lower the ratio of cortical excitation to cortical inhibition. Lowfrequency rTMS over DLPFC may therefore lead to improvement in executive functions due to stronger lateral inhibition and enhanced functional connectivity that may lead to improvement in frontolimbic functions, leading to restoration of the normative inhibitory top-down control exerted by the frontal structures.

In previous studies we have reported on the positive effects of rTMS in autism using a large variety of outcome measures (Baruth et al., 2010, 2011; Casanova et al., 2012, 2015; Sokhadze et al., 2009, 2012, 2014, 2016; Wang et al., 2016). For better understanding of potential mechanisms of TMS neuromodulation effects on autonomic activity, it is necessary to consider the interaction between the central and autonomic nervous systems. The Central autonomic network (CAN) model proposed by Thayer and Lane (2000) describes how neural structures involved in cognitive, affective, and autonomic regulation are related to HRV and cognitive performance. In this model, the anatomical details of a CAN are described, linking the nucleus of the solitary tract in the brainstem with forebrain structures including the anterior cingulate cortex, insula, ventromedial PFC, amygdala, and hypothalamus through feedback and feed-forward loops. Thayer et al. (2012) outlined connections between the amygdala and medial prefrontal cortex (mPFC), which evaluate stimuli in the context of threat and safety and which regulate HRV through their connections with the nucleus of the solitary tract. Furthermore, the CAN model proposes that vagally-mediated HRV is linked to prefrontal executive functions and that HRV reflects the functional capacity of the PFC to support emotional and physiological self-regulation. It was hypothesized that parasympathetically mediated HRV is positively correlated with prefrontal cortical performance; thus, when prefrontal cortical functioning is decreased, HR increases and HRV decreases. Prolonged prefrontal cortical inactivity can lead to hypervigilance, defensiveness, and social isolation (Thayer, Hansen, Saus-Rose, \& Johnsen, 2009). The CAN model predicts reduced HRV and hypofunctional vagal activity in anxiety, as it might be associated with abnormal ANS cardiac control (Friedman, 2007). This approach challenges the sympathetic overarousal model of anxiety that overlooks the role of a hypofunctional parasympathetic system. From this perspective, disorders presenting with anxiety and dysregulated autonomic control can involve varying degrees of sympathetic overactivation and parasympathetic underactivation. The main point is to account for 
both autonomic branches' activation status in research aimed at understanding the nature of autonomic dysfunction.

The strategy for the selected intervention, considering the CAN model, is that neuromodulation of the DLPFC using low-frequency rTMS can increase the PFC's ability to exercise top-down control of emotional responses. Due to a cascading effect caused by the anatomical and functional connectivity of this integrative prefrontal brain region, we expected the TMS-based intervention not to be limited to the site of magnetic stimulation but rather to generalize to other cortical and subcortical areas including those directly involved in autonomic arousal control. Biophysical foundations underlying TMS effects are reviewed in Wagner, Rushmore, Eden, and Valero-Cabre (2009), while effects of TMS on connectivity of the cortical structures are reviewed in Paus et al. (1997). Results of our pilot studies (Sokhadze et al., 2009, 2016) showed changes of event-related potentials and induced electroencephalographic (EEG) gamma oscillations that occurred not only in the frontal lobe but also in distal cortical areas (e.g., parietal, parieto-occipital). Effects of rTMS over DLPFC are possibly extended to paralimbic and limbic structures as well and may manifest themselves in ANS activity changes.

Brain functions involved in the generation and representation of arousal state have been linked to social cognition in typical development (Critchley, 2005), suggesting that they may be important to disorders of social interaction such as ASD. According to Critchley (2005), emotional and cognitive processes evoke patterned changes in profiles of physiological measures that may signal a particular emotional state. The modulation of the visceral state is mediated by the sympathetic and parasympathetic divisions of the ANS. Moreover, neural afferents support and convey representations of the internal state of the body to the brain to further influence emotion and cognition. Feedback from the viscera is mapped in the brain to influence efferent neural signals and, at the cortical level, to reinforce affective responses and emotional states. The discrete cortical substrates for these representations include the anterior regions of the insula and orbitofrontal cortex, areas that have direct connections with the DLPFC. The misperception of heightened arousal level (either over- or underestimation of actual autonomic arousal level status) may readily evoke significant changes in emotional behavior. Cognitive processes such as decision-making are guided by central feedback of bodily arousal responses (Damasio, Everitt, \&
Bishop, 1996). The influence of transient arousal responses on aspects of affect and cognition is embodied within Damasio's "Somatic Marker Hypothesis" which proposes that emotional feelings originate in mental representations within the somatosensory cortices (Damasio et al., 1996). Empirical studies have implicated the insular cortex as the substrate for emotional states, supported by activity within the amygdala, anterior cingulate cortex, and orbital prefrontal regions-structures which communicate directly with the DLPFC. The anterior insula and ventromedial prefrontal cortex contribute to the integration of visceral afferent information. These observations also map into the insula theory of anxiety of Paulus and Stein (2006), who propose that feelings of anxiety emerge through mismatched representation of anticipated and perceived bodily states within the insular cortex. The role of the heightened sympathetic arousal and reduced vagal afferent activity biasing normal autonomic/visceral state representations therefore may negatively affect emotional reactivity in individuals with ASD.

There are several limitations of this study that need to be noted. The study was not controlled, as it was not randomized and did not use a sham rTMS group, and as such represents a continuation of our case series studies. Furthermore, we measured only tonic resting state autonomic activity during rTMS procedure. Considering that the differences between children with ASD and typically developing children are reported not only in tonic basal autonomic arousal level but also in phasic autonomic responses to various stimuli, it would be important to have a comparison in autonomic reactivity as well. The age range in our cohort was quite wide, even though our statistical analysis of age-related factor yielded age differences only in peaks of VLF and LF of HRV. Medication status of all subjects was monitored but not included as a confounding factor in statistical analysis. Ratio of boys vs. girls was $3.5: 1$, which was probably the reason why we could not find any gender-related factor effects on rTMS course outcomes. Our future studies will address limitations listed above by adding sham-TMS group, stratified blinded randomization of children with ASD into active and sham-TMS groups, and a battery of psychophysiological tests pre- and posttreatment. We plan also to recruit subjects with more restricted age eligibility range to rule out age-related factor influences. 


\section{Conclusion}

In general, complementing rTMS treatment with concurrent monitoring of autonomic functions may advance neuromodulation approaches in other psychiatric and neurological disorders as well, especially in those where rTMS treatment has been shown to be effective (e.g., major depression, obsessive compulsive disorder, schizophrenia, Parkinson disease).

The current theory-guided pilot study was based on a hypothesis proposing that rTMS over the DLPFC improves cortical excitation/inhibition ratio in autism and enhances prefrontal functioning, including enhancing normative prefrontal inhibitory influences on the limbic system and subcortical centers controlling level of autonomic arousal. We propose that the application of rTMS has potential to be considered as a novel, customizable neurotherapeutic tool targeting autonomic balance that may positively affect the social and behavior deficits as well as the hyperactivity and anxiety problems experienced by children and adolescents with autism. In addition, this tool could serve as a platform for the development of treatments of other childhood anxiety disorders.

We believe that the application of neuromodulation techniques to increase parasympathetic activity and lower sympathetic activity is a potentially powerful approach to treating some symptoms of autism. Our underlying rationale for using rTMS in children with autism links cardiac underreactivity in socially engaging situations to dysfunctions in cardiac autonomic regulation in autism which results in a reduced attentional capacity to attend socially relevant stimuli critical for effective communication with peers. This hypothesis outlines an important role of the ANS in emotional reactivity and social behavior. Poor control of HR and vulnerability to tachycardia is an important consequence of chronic increased sympathetic activity and decreased vagal tone (Berntson et al., 1997; Corona et al., 1998; Friedman \& Thayer, 1998; Thayer et al., 2012). The baseline sympathetic arousal found in autism may be a condition of disinhibition, resulting from compromised baseline parasympathetic inhibition. Reduced frontolimbic connectivity and poor prefrontal tonic inhibitory control over the limbic system might be one of the reasons for excessive excitation of the sympathetic system in ASD. TMS could be an effective technique for restoring regulation of parasympathetic activity and for improving sympatho-vagal cardiac balance in autism. It may also result in restoration of normative visceral representations thought to be distorted in autism due to chronic sympathetic overarousal.

Future randomized clinical trials with blinding and sham TMS control conditions may help in establishing rTMS as a neuromodulatory treatment aimed to regulate autonomic balance in children with ASD. The current study is an early step aimed at demonstrating the feasibility of this approach and a call for further exploration and rigorous, controlled clinical trials.

\section{Author Notes}

The study was partially supported by National Institutes of Health Eureka R01 grant R01MH86784 and FERB graduate student grant.

\section{References}

Althaus, M., Mulder, L. J. M., Mulder, G., Aarnoudse, C. C., \& Minderaa, R. B. (1999). Cardiac adaptivity to attentiondemanding tasks in children with a pervasive developmental disorder not otherwise specified (PDD-NOS). Biological Psychiatry, 46(6), 799-809. http://dx.doi.org/10.1016/S00063223(98)00374-6

Aman, M. G., \& Singh, N. N. (1994). Aberrant behavior checklist - community. Supplementary Manual. East Aurora, NY: Slosson Educational Publications.

American Psychiatric Association. (2013). Diagnostic and Statistical Manual of Mental Disorders (5th ed.). Washington, DC: $\quad$ Author. $\quad \mathrm{http}: / / \mathrm{dx}$.doi.org/10.1176 lappi.books.9780890425596

Bachevalier, J., \& Loveland, K. A. (2006). The orbitofrontalamygdala circuit and self-regulation of social-emotional behavior in autism. Neuroscience \& Biobehavioral Reviews, 30(1), 97-117. http://dx.doi.org/10.1016 /j.neubiorev.2005.07.002

Barry, R. J., \& James, A. L. (1988). Coding of stimulus parameters in autistic, retarded, and normal children: Evidence for a two-factor theory of autism. International Journal of Psychophysiology, 6(2), 139-149. http://dx.doi.org /10.1016/0167-8760(88)90045-1

Baruth, J. M., Casanova, M. F., El-Baz, A., Horrell, T., Mathai, G., Sears, L., \& Sokhadze, E. (2010). Low-frequency repetitive transcranial magnetic stimulation modulates evoked-gamma frequency oscillations in autism spectrum disorders. Journal of Neurotherapy, 14(3), 179-194. https://dx.doi.org/10.1080 $/ 10874208.2010 .501500$

Baruth, J., Williams, E., Sokhadze, E., El-Baz, A., Sears, L., \& Casanova, M. F. (2011). Repetitive transcranial stimulation (rTMS) improves electroencephalographic and behavioral outcome measures in autism spectrum disorders (ASD). Autism Science Digest, 1(1), 52-57.

Benevides, T. W., \& Lane, S. J. (2015). A review of cardiac autonomic measures: considerations for examination of physiological response in children with autism spectrum disorder. Journal of Autism and Developmental Disorders, 45(2), 560-575. http://dx.doi.org/10.1007/s10803-013-1971-z

Ben-Shachar, D., Belmaker, R. H., Grisaru, N., \& Klein, E. (1997). Transcranial magnetic stimulation induces alterations in brain monoamines. Journal of Neural Transmission, 104(2-3), 191-197. http://dx.doi.org/10.1007/BF01273180

Berntson, G. G., Bigger, J. T., Eckberg, D. L., Grossman, P., Kaufmann, P. G., Malik, M., ... Van der Molen, M. W. (1997). Heart rate variability: Origins, methods, and interpretive 
caveats. Psychophysiology, 34(6), 623-648. http://dx.doi.org /10.1111/j.1469-8986.1997.tb02140.x

Bodfish, J. W., Symons, F. J., \& Lewis, M. H. (1999). Repetitive behavior scale. Morganton, NC: Western Carolina Center Research Reports.

Boucsein, W. (2012). Electrodermal activity (2nd ed.). New York, NY: Springer. http://dx.doi.org/10.1007/978-1-4614-1126-0

Casanova, M. F. (2005). Minicolumnar pathology in autism. In M. F. Casanova (Ed.), Recent developments in autism research (pp.133-144). New York, NY: Nova Biomedical Books.

Casanova, M. F. (2006). Neuropathological and genetic findings in autism: The significance of a putative minicolumnopathy. The Neuroscientist, 12(5), 435-441. http://dx.doi.org/10.1177 $/ 1073858406290375$

Casanova, M. F., Baruth, J. M., El-Baz, A., Tasman, A., Sears, L., \& Sokhadze, E. (2012). Repetitive transcranial magnetic stimulation (rTMS) modulates event-related potential (ERP) indices of attention in autism. Translational Neuroscience, 3(2), 170-180. http://dx.doi.org/10.2478/s13380-012-0022-0

Casanova, M. F., Buxhoeveden, D. P., \& Brown, C. (2002). Clinical and macroscopic correlates of minicolumnar pathology in autism. Journal of Child Neurology, 17(9), 692695. http://dx.doi.org/10.1177/088307380201700908

Casanova, M. F., Buxhoeveden, D., \& Gomez, J. (2003). Disruption in the inhibitory architecture of the cell minicolumn: Implications for autism. The Neuroscientist, 9(6), 496-507. https://dx.doi.org/10.1177/1073858403253552

Casanova, M. F., Hensley, M. K., Sokhadze, E. M., El-Baz, A. S., Wang, Y., Li, X., \& Sears, L. (2014). Effects of weekly lowfrequency rTMS on autonomic measures in children with autism spectrum disorder. Frontiers in Human Neuroscience, 8, 851. http://dx.doi.org/10.3389/fnhum.2014.00851

Casanova, M. F., Sokhadze, E., Opris, I., Wang, Y., \& Li, X (2015). Autism spectrum disorders: Linking neuropathological findings to treatment with transcranial magnetic stimulation. Acta Pædiatrica, 104(4), 346-355. http://dx.doi.org/10.1111 lapa.12943

Casanova, M. F., van Kooten, I. A. J., Switala, A. E., van Engeland, H., Heinsen, H., Steinbusch, H. W., ... Schmitz, C. (2006). Minicolumnar abnormalities in autism. Acta Neuropathologica, 112(3), 287-303. http://dx.doi.org/10.1007 /s00401-006-0085-5

Chang, M. C., Parham, L. D., Blanche, E. I., Schell, A., Chou, C.P., Dawson, M., \& Clark, F. (2012). Autonomic and behavioral responses of children with autism to auditory stimuli. American Journal of Occupational Therapy, 66(5), 567-576. http://dx.doi.org/10.5014/ajot.2012.004242

Cohen, H., Benjamin, J., Geva, A. B., Matar, M. A., Kaplan, Z., \& Kotler, M. (2000). Autonomic dysregulation in panic disorder and in post-traumatic stress disorder: Application of power spectrum analysis of heart rate variability at rest and in response to recollection of trauma or panic attack. Psychiatry Research, 96(1), 1-13. http://dx.doi.org/10.1016/S01651781(00)00195-5

Cohen, S., Masyn, K., Mastergeorge, A., \& Hessl, D. (2015). Psychophysiological responses to emotional stimuli in children and adolescents with autism and fragile $X$ syndrome. Journal of Clinical Child \& Adolescent Psychology, 44(2), 250-263. http://dx.doi.org/10.1080/15374416.2013.843462

Constantino, J. N., \& Gruber, C. P. (2005). The social responsiveness scale (SRS): Manual. Los Angeles, CA: Western Psychological Services.

Corona, R., Dissanayake, C., Arbelle, S., Wellington, P., \& Sigman, M. (1998). Is affect aversive to young children with autism? Behavioral and cardiac responses to experimenter distress. Child Development, 69(6), 1494-1502. http://dx.doi.org/10.1111/j.1467-8624.1998.tb06172.x

Critchley, H. D. (2005). Neural mechanisms of autonomic, affective, and cognitive integration. The Journal of
Comparative Neurology, 493(1), 154-166. https://dx.doi.org /10.1002 /cne.20749

Czéh, B., Welt, T., Fischer, A. K., Erhardt, A., Schmitt, W., Müller M. B., ... Keck, M. E. (2002). Chronic psychosocial stress and concomitant repetitive transcranial magnetic stimulation: Effects on stress hormone levels and adult hippocampal neurogenesis. Biological Psychiatry, 52(11), 1057-1065. http://dx.doi.org/10.1016/S0006-3223(02)01457-9

Damasio, A. R., Everitt, B. J., \& Bishop, D. (1996). The somatic marker hypothesis and the possible functions of the prefrontal cortex. Philosophical Transactions of the Royal Society of London, Biological Sciences, 351(1346), 1413-1420. http://dx.doi.org/10.1098/rstb.1996.0125

Dombroski, B., Kaplan, M., Kotsamanidis-Burg, B., Edelson, S. M., Hensley, M. K., Sokhadze, E. M., \& Casanova, M. F. (2014). Effects of ambient prism lenses and visual-motor training on heart rate variability and behavioral outcomes in autism. In K. Siri and T. Lyons (Eds.), Cutting-edge therapies for autism (4th ed., pp.138-150). New York, NY: Skyhorse Publishing.

Filippi, M. M., Oliveri, M., Vernieri, F., Pasqualetti, P., \& Rossini, P. M. (2000). Are autonomic signals influencing cortico-spinal motor excitability? A study with transcranial magnetic stimulation. Brain Research, 881(2), 159-164. http://dx.doi.org/10.1016/S0006-8993(00)02837-7

Friedman, B. H. (2007). An autonomic flexibility-neurovisceral integration model of anxiety and cardiac vagal tone. Biological Psychology, 74(2), 185-199. http://dx.doi.org/10.1016 /j.biopsycho.2005.08.009

Friedman, B. H., \& Thayer, J. F. (1998). Anxiety and autonomic flexibility: A cardiovascular approach. Biological Psychology, 49(3), 303-323. $\quad$ https://doi.org/10.1016/S03010511(97)00027-6

George, M. S., Lisanby, S. H., \& Sackeim, H. A. (1999). Transcranial magnetic stimulation: Applications in neuropsychiatry. Archives of General Psychiatry, 56(4), 300311. http://dx.doi.org/10.1001/archpsyc.56.4.300

Gillott, A., Furniss, F., \& Walter, A. (2001). Anxiety in highfunctioning children with autism. Autism, 5(3), 277-286. http://dx.doi.org/10.1177/1362361301005003005

Hedges, D. W., Salyer, D. L., Higginbotham, B. J., Lund, T. D., Hellewell, J. L., Ferguson, D., \& Lephart, E. D. (2002). Transcranial magnetic stimulation (TMS) effects on testosterone, prolactin, and corticosterone in adult male rats. Biological Psychiatry, 51(5), 417-421. http://dx.doi.org /10.1016/S0006-3223(01)01266-5 - blank

Helverschou, S. B., \& Martinsen, H. (2011). Anxiety in people diagnosed with autism and intellectual disability: Recognition and phenomenology. Research in Autism Spectrum Disorders, 5(1), 377-387. http://dx.doi.org/10.1016 /j.rasd.2010.05.003

Hensley, M., El-Baz, A., Casanova, M. F., \& Sokhadze, E. (2013). Heart rate variability and cardiac autonomic measures changes during rTMS in autism. Applied Psychophysiology and Biofeedback, 38, 238.

Hensley, M., El-Baz, A., Sokhadze, G., Sears, L., Casanova, M. F., \& Sokhadze, E. M. (2012). TMS effects on cardiac autonomic control in children with autism. Psychophysiology, $49,540$.

Hirstein, W., Iversen, P., \& Ramachandran, V. S. (2001). Autonomic responses of autistic children to people and objects. Proceedings of the Royal Society of London, Biological Sciences, 268(1479), 1883-1888. http://dx.doi.org /10.1098/rspb.2001.1724

Holsboer, F. (2000). The corticosteroid receptor hypothesis of depression. Neuropsychopharmacology, 23(5), 477-501. http://dx.doi.org/10.1016/S0893-133X(00)00159-7

Hutt, C., Forrest, S. J., \& Richer, J. (1975). Cardiac arrhythmia and behavior in autistic children. Acta Psychiatrica 
Scandinavica, 51(5), 361-372. http://dx.doi.org/10.1111 /j.1600-0447.1975.tb00014.x

Jansen, L. M. C., Gispen-de Wied, C. C., Van der Gaag, R. J., ten Hove, F., Willemsen-Swinkels, S. W. M., Harteveld, E., \& Van Engeland, H. (2000). Unresponsiveness to psychosocial stress in a subgroup of autistic-like children, Multiple Complex Developmental Disorder. Psychoneuroendocrinology, 25(8), 753-764. http://dx.doi.org/10.1016/S0306-4530(00)00020-2

Jenkins, J., Shajahan, P. M., Lappin, J. M., \& Ebmeier, K. P. (2002). Right and left prefrontal transcranial magnetic stimulation at $1 \mathrm{~Hz}$ does not affect mood in healthy volunteers. BMC Psychiatry, 2(1). http://dx.doi.org/10.1186 11471-244X-2-1

Julu, P. O. O., Kerr, A. M., Apartopoulos, F., Al-Rawas, S., Engerström, I. W., Engerström, L., ... Hansen, S. (2001). Characterization of breathing and associated central autonomic dysfunction in the Rett disorder. Archives of Disease in Childhood, 85(1), 29-37. http://dx.doi.org /10.1136/adc.85.1.29

Keehn, B., Müller, R.-A., \& Townsend, J. (2013). Atypical attentional networks and the emergence of autism. Neuroscience \& Biobehavioral Reviews, 37(2), 164-183. http://dx.doi.org/10.1016/j.neubiorev.2012.11.014

Kleberg, J. L. (2015). Resting state arousal and functional connectivity in autism spectrum disorder. Journal of Neurophysiology, 113(9), 3035-3037. http://dx.doi.org /10.1152/jn.00292.2014

Kleiger, R. E., Stein, P. K., \& Bigger, J. T., Jr. (2005). Heart rate variability: Measurement and clinical utility. Annals of Noninvasive Electrocardiology, 10(1), 88-101. http://dx.doi.org/10.1111/j.1542-474X.2005.10101.x

Kushki, A., Brian, J., Dupuis, A., \& Anagnostou, E. (2014). Functional autonomic nervous system profile in children with autism spectrum disorder. Molecular Autism, 5(1), 39. http://dx.doi.org/10.1186/2040-2392-5-39

Kushki, A., Drumm, E., Mobarak, M. P., Tanel, N., Dupuis, A., Chau, T., \& Anagnostou, E. (2013). Investigating the autonomic nervous system response to anxiety in children with autism spectrum disorders. PLOS ONE, 8(4), e59730. https://dx.doi.org/10.1371/journal.pone.0059730

Lacey J. I., \& Lacey, B. C. (1970). Some autonomic-central nervous system interrelationships. In $P$. Black (Ed.), Physiological correlates of emotion (pp. 205-227). New York, NY: Academic Press. http://dx.doi.org/10.1016/B978-0-12102850-3.50016-5

LeCouteur, A., Lord, C., \& Rutter, M. (2003). The autism diagnostic interview - Revised (ADI-R). Los Angeles, CA: Western Psychological Services.

Liss, M., Saulnier, C., Fein, D., \& Kinsbourne, M. (2006). Sensory and attention abnormalities in autistic spectrum disorders. Autism, 10(2), 155-172. http://dx.doi.org/10.1177 $/ 1362361306062021$

Loveland, K. A., Bachevalier, J., Pearson, D. A., \& Lane, D. M. (2008). Fronto-limbic functioning in children and adolescents with and without autism. Neuropsychologia, 46(1), 49-62. http://dx.doi.org/10.1016/j.neuropsychologia.2007.08.017

Malliani, A., Pagani, M., \& Lombardi, F. (1994). Physiology and clinical implications of variability of cardiovascular parameters with focus on heart rate and blood pressure. The American Journal of Cardiology, 73(10), C3-C9. http://dx.doi.org /10.1016/0002-9149(94)90617-3

Ming, X., Bain, J. M., Smith, D., Brimacombe, M., Gold vonSimson, G., \& Axelrod, F. B. (2011). Assessing autonomic dysfunction symptoms in children: A pilot study. Journal of Child Neurology, 26(4), 420-427. http://dx.doi.org/10.1177 10883073810381921

Ming, X., Julu, P. O. O., Brimacombe, M., Connor, S., \& Daniels, M. L. (2005). Reduced cardiac parasympathetic activity in children with autism. Brain \& Development, 27(7), 509-516. http://dx.doi.org/10.1016/j.braindev.2005.01.003
Ming, X., Julu, P. O. O., Wark, J., Apartopoulos, F., \& Hansen, S. (2004). Discordant mental and physical efforts in an autistic patient. Brain \& Development, 26(8), 519-524. http://dx.doi.org/10.1016/j.braindev.2004.02.005

Ming, X., Patel, R., Kang, V., Chokroverty, S., \& Julu, P. O. (2016). Respiratory an autonomic dysfunction in children with autism spectrum disorders. Brain \& Development, 38(2), 225232. http://dx.doi.org/10.1016/j.braindev.2015.07.003

Mountcastle, V. B. (2003). Introduction. Computation in cortical columns. Cerebral Cortex, 13(1), 2-4. http://dx.doi.org /10.1093/cercor/13.1.2

Movius, H. L., \& Allen, J. J. B. (2005). Cardiac Vagal Tone, defensiveness, and motivational style. Biological Psychology, 68(2), 147-162. http://dx.doi.org/10.1016 /j.biopsycho.2004.03.019

Orekhova, E. V., \& Stroganova, T. A. (2014). Arousal and attention re-orienting in autism spectrum disorders: Evidence from auditory event-related potentials. Frontiers in Human Neuroscience, $\quad 8, \quad 34 . \quad$ http://dx.doi.org/10.3389 /fnhum.2014.00034

Pagani, M., Lombardi, F., Guzzetti, S., Rimoldi, O., Furlan, R., Pizzinelli, P., ... Piccaluga, E. (1986). Power spectral analysis of heart rate and arterial pressure variabilities as a marker of sympatho-vagal interaction in man and conscious dog. Circulation Research, 59(2), 178-193. http://dx.doi.org /10.1161/01.RES.59.2.178

Palkovitz, R. J., \& Wiesenfeld, A. R. (1980). Differential autonomic responses of autistic and normal children. Journal of Autism and Developmental Disorders, 10(3), 347-360. http://dx.doi.org/10.1007/BF02408294

Pascual-Leone, A., Walsh, V., \& Rothwell, J. (2000). Transcranial magnetic stimulation in cognitive neuroscience-Virtual lesion, chronometry, and functional connectivity. Current Opinion in Neurobiology, 10(2), 232-237. http://dx.doi.org /10.1016 /S0959-4388(00)00081-7 - blank

Patriquin, M. A., Lorenzi, J., \& Scarpa, A. (2013). Relationship between respiratory sinus arrhythmia, heart period, and caregiver-reported language and cognitive delays in children with autism spectrum disorders. Applied Psychophysiology and Biofeedback, 38(3), 203-207. http://dx.doi.org/10.1007 /s10484-013-9225-6

Paulus, M. P., \& Stein, M. B. (2006). An insular view of anxiety. Biological Psychiatry, 60(4), 383-387. http://dx.doi.org /10.1016/j.biopsych.2006.03.042

Paus, T., Jech, R., Thompson, C. J., Comeau, R., Peters, T., \& Evans, A. C. (1997). Transcranial magnetic stimulation during positron emission tomography: A new method for studying connectivity of the human cerebral cortex. The Journal of Neuroscience, 17(9), 3178-3184

Porges, S. W. (1995). Orienting in a defensive world: Mammalian modifications of our evolutionary heritage. A Polyvagal Theory. Psychophysiology, 32(4), 301-318. http://dx.doi.org /10.1111/j.1469-8986.1995.tb01213.x

Porges, S. W. (2003). The Polyvagal Theory: Phylogenetic contributions to social behavior. Physiology \& Behavior, 79(3), $\quad$ 503-513. http://dx.doi.org/10.1016/S0031. 9384(03)00156-2

Porges, S. W. (2011). The polyvagal theory: Neurophysiological foundations of emotions, attachment, communication, and self-regulation. New York, NY: W. W. Norton \& Co.

Porges, S. W., Doussard-Roosevelt, J. A., Portales, A. L., \& Greenspan, S. I. (1996). Infant regulation of the vagal "brake" predicts child behavioral problems: A psychobiological model of social behavior. Developmental Psychobiology, 29(8), 697712 . http://dx.doi.org/10.1002/(SICl)10982302(199612)29:8<697::AID-DEV5>3.0.CO;2-O

Rees, C. A. (2014). Lost among trees? The autonomic nervous system and paediatrics. Archives of Disease in Childhood, 99(6), 552-562. http://dx.doi.org/10.1136/archdischild-2012301863 
Rogers, S. J., \& Ozonoff, S. (2005). Annotation: What do we know about sensory dysfunction in autism? A critical review of the empirical evidence. The Journal of Child Psychology and Psychiatry, 46(12), 1255-1268. http://dx.doi.org/10.1111 /j.1469-7610.2005.01431.x

Rubenstein, J. L. R., \& Merzenich, M. M. (2003). Model of autism: Increased ratio of excitation/inhibition in key neural systems. Genes, Brain, and Behavior, 2(5), 255-267. http://dx.doi.org /10.1034/j.1601-183X.2003.00037.x

Seminowicz, D. A., Mayberg, H. S., McIntosh, A. R., Goldapple, K., Kennedy, S., Segal, Z., \& Rafi-Tari, S. (2004). Limbicfrontal circuitry in major depression: A path modeling metaanalysis. Neurolmage, 22(1), 409-418. http://dx.doi.org /10.1016/j.neuroimage.2004.01.015

Schoen, S. A., Miller, L. J., Brett-Green, B. A., \& Nielsen, D. M. (2009). Physiological and behavioral differences in sensory processing: A comparison of children with autism spectrum disorder and sensory modulation disorder. Frontiers in Integrative Neuroscience, 3, 29. http://dx.doi.org/10.3389 /neuro.07.029.2009

Smeekens, I., Didden, R., \& Verhoeven, E. W. M. (2015) Exploring the relationship of autonomic and endocrine activity with social functioning in adults with autism spectrum disorders. Journal of Autism and Developmental Disorders, 45(2), 495-505. http://dx.doi.org/10.1007/s10803-013-1947-z

Sohn, J.-H., Sokhadze, E., \& Watanuki, S. (2001). Electrodermal and cardiovascular manifestations of emotions in children. Journal of Physiological Anthropology and Applied Human Science, 20(2), 55-64. http://dx.doi.org/10.2114/jpa.20.55

Sokhadze, E. M., Casanova, M. F., El-Baz, A. S., Farag, H. E., Li, X., \& Wang, Y. (2016). TMS-based neuromodulation of evoked and induced gamma oscillations and event-related potentials in children with autism. NeuroRegulation, 3(3), 101-126. http://dx.doi.org/10.15540/nr.3.3.101

Sokhadze, E. M., El-Baz, A., Baruth, J., Mathai, G., Sears, L., \& Casanova, M. F. (2009). Effects of low-frequency repetitive transcranial magnetic stimulation (rTMS) on gamma frequency oscillations and event-related potentials during processing of illusory figures in autism. Journal of Autism and Developmental Disorders, 39(4), 619-634. http://dx.doi.org /10.1007/s10803-008-0662-7

Sokhadze, E. M., El-Baz, A. S., Tasman, A., Sears, L. L., Wang, Y., Lamina, E. V., \& Casanova, M. F. (2014). Neuromodulation integrating rTMS and neurofeedback for the treatment of autism spectrum disorder: An exploratory study. Applied Psychophysiology and Biofeedback, 39(3-4), 237257. http://dx.doi.org/10.1007/s10484-014-9264-7

Sokhadze, G., Kaplan, M., Sokhadze, E. M., Edelson, S. M., Baruth, J., El-Baz, A. S., ... Casanova, M. F. (2012). Effects of ambient prism lenses on autonomic reactivity to emotional stimuli in autism. Applied Psychophysiology and Biofeedback, 37, 303.

Thayer, J. F., Ahs, F., Fredrikson, M., Sollers, J. J., \& Wager, T. D. (2012). A meta-analysis of heart rate variability and neuroimaging studies: Implications for heart rate variability as a marker of stress and health. Neuroscience \& Biobehavioral Reviews, 36(2), 747-756. http://dx.doi.org/10.1016 /j.neubiorev.2011.11.009

Thayer, J. F., \& Friedman, B. H. (2002). Stop that! Inhibition, sensitization, and their neurovisceral concomitants. Scandinavian Journal of Psychology, 43(2), 123-130. http://dx.doi.org/10.1111/1467-9450.00277

Thayer, J. F., Hansen, A. L., Saus-Rose, E., \& Johnsen, B. H. (2009). Heart rate variability, prefrontal neural function, and cognitive performance: The neurovisceral integration perspective on self-regulation, adaptation, and health. Annals of Behavioral Medicine, 37(2), 141-153. http://dx.doi.org /10.1007/s12160-009-9101-z

Thayer, J. F., \& Lane, R. D. (2000). A model of neurovisceral integration in emotion regulation and dysregulation. Journal of Affective Disorders, 61(3), 201-216. http://dx.doi.org /10.1016/S0165-0327(00)00338-4

Toichi, M., \& Kamio, Y. (2003). Paradoxical autonomic response to mental tasks in autism. Journal of Autism and Developmental Disorders, 33(4), 417-426. http://dx.doi.org /10.1023/A:1025062812374

Toichi, M., Kubota, Y., Murai, T., Kamio, Y., Sakihama, M., Toriuchi, T., ... Miyoshi, K. (1999). The influence of psychotic states on the autonomic nervous system in schizophrenia International Journal of Psychophysiology, 31(2), 147-154. http://dx.doi.org/10.1016/S0167-8760(98)00047-6

Udupa, K., Sathyaprabha, T. N., Thirthalli, J., Kishore, K. R., Raju, T. R., \& Gangadhar, B. N. (2007). Modulation of cardiac autonomic functions in patients with major depression treated with repetitive transcranial magnetic stimulation. Journal of Affective Disorders, 104(1-3), 231-236. https://dx.doi.org /10.1016/j.jad.2007.04.002

van Engeland, H. (1984). The electrodermal orienting response to auditive stimuli in autistic children, normal children, mentally retarded children, and child psychiatric patients. Journal of Autism and Developmental Disorders, 14(3), 261-279. http://dx.doi.org/10.1007/BF02409578

Wagner, T., Rushmore, J., Eden, U., \& Valero-Cabre, A. (2009). Biophysical foundations underlying TMS: Setting the stage for an effective use of neurostimulation in the cognitive neurosciences. Cortex, 45(9), 1025-1034. http://dx.doi.org /10.1016/j.cortex.2008.10.002

Wang, Y., Hensley, M. K., Tasman, A., Sears, L., Casanova, M. F., \& Sokhadze, E. M. (2016). Heart rate variability and skin conductance during repetitive TMS course in children with autism. Applied Psychophysiology and Biofeedback, 41(1), 47-60. http://dx.doi.org/10.1007/s10484-015-9311-z

Wechsler, D. (2004). Wechsler intelligence scale for childrenFourth edition integrated (WISC-IV Integrated). San Antonio, TX: Harcourt Assessment Inc.

Williams, L. M., Brown, K. J., Das, P., Boucsein, W., Sokolov, E. N., Brammer, M. J., ... Gordon, E. (2004). The dynamics of cortico-amygdala and autonomic activity over the experimental time course of fear perception. Cognitive Brain Research, 21(1), 114-123. http://dx.doi.org/10.1016 /j.cogbrainres.2004.06.005

Yoshida, T., Yoshino, A., Kobayashi, Y., Inoue, M., Kamakura, K., \& Nomura, S. (2001). Effects of slow repetitive transcranial magnetic stimulation on heart rate variability according to power spectrum analysis. Journal of the Neurological Sciences, 184(1), 77-80. http://dx.doi.org/10.1016/S0022$510 \times(00) 00505-0$

Zahn, T. P., Rumsey, J. M., \& Van Kammen, D. P. (1987). Autonomic nervous system activity in autistic, schizophrenic, and normal men: effects of stimulus significance. Journal of Abnormal Psychology, 96(2), 135-144. http://dx.doi.org /10.1037/0021-843X.96.2.135

Received: March 10, 2017

Accepted: April 3, 2017

Published: June 30, 2017 